Marinete Marins Póvoa 1 José Eduardo Gomes Arruda 1 Mônica Cristina de Moraes Silva 1,4 Cléa Nazaré Carnei ro Bichara 1 Paulo Esteves 2 Yvone Benchimol Gabbay 3 Ricardo Luiz Dantas Machado 1

\section{Diagnóstico de amebíase intestinal utilizando métodos coproscópicos e imunológicos em amostra da população da área metropolitana de Belém, Pará, Brasil}

\author{
Diagnosis of intestinal amebiasis using \\ coproscopic and immunological methods \\ in a population sample in Greater Metropolitan \\ Belém, Pará, Brazil
}

\footnotetext{
1 Laboratório de Enteroparasitoses, Serviço de Parasi tol ogia, Instituto Evandro Chagas. Av. Almirante Barroso 492, Belém, PA

66090-000, Brasil. marinete@iec.pa.gov.br

2 Hospital da Polícia Militar de Belém. Rua dos Mundurucus 1770, Belém, PA 66045-000, Brasil. 3 Serviço de Virologia, Instituto Evandro Chagas. Av. Almirante Barroso 492, Belém, PA 66090-000, Brasil. 4 Centro de Ensino Superior do Pará. Rua Oliveira Belo 454 Belém, PA 66000-030, Brasil.
}

\begin{abstract}
We compare diagnostic methods for Entamoeba histolytica in fecal samples from the city of Belém, Pará, Brazil. We analyze stool samples from children and adults (Group I); stool and serum samples from adults (Group II); and stool samples from children (Group III). In groups I and III, we used direct examination with lugol (DM), Faust et al (FM), and ELISA (detection of E. histolytica anti-GIAP coproantigen) and in group II, DM, iron hematoxyl in staining (IHS), FM, ELISA, and the indirect immunofluorescence test (IFAT) for detection of IgG antibodies. Positivity was $10.50 \%$ by DM plus FM and $28.99 \%$ by ELISA. There was no correlation between positivity and age group. In Group II ( $\mathrm{n}=87$ ), the positive rate was $4.59 \%$ by DM plus FM, $8.04 \%$ by IHS, $4.59 \%$ by IFAT, and $21.83 \%$ by ELISA. The ELISA test was the most sensitive for all groups. IFAT alone is still not a useful tool for diagnosis of E. histolytica infection. The ELISA test is simple, performed in one third of cases used for IHS and IFAT, and greatly improves quality of diagnosis. We recommend this as the method of choi ce for diagnosi s of suspected E. histolytica infection.

Key words Entamoeba histolytica; Amebiasis; Diagnosis; Enzyme-Linked Immunosorbent Assay

Resumo O artigo expõe a comparação de métodos de diagnóstico de Entamoeba histolytica em amostra da população de Belém do Pará. Foram anali sadas amostras fecais de crianças e adultos (Grupo I), amostras fecais e soros de adultos (Grupo II) e material fecal de crianças (Grupo III). Nos grupos I ellI foram empregados os métodos direto com lugol (MD), Faust e cols. (MFF) e ELISA (detecção de coproantígeno anti-GIAP de E. histolytica); no grupo II, MD, hematoxilina férrica (HF), MFF, ELISA e reação de imunofluorescência indireta (RIFI) para detecção de anticorpos IgG. A positividade encontrada foi de 10,50\%, empregando (MD + MFF) e de 28,99\% pelo ELISA. Não houve correl ação entre posi tividade e grupo etário. No Grupo II ( $n=87$ ), a positividade encontrada foi de 4,59\% pel os métodos coproscópicos (MD + MFF), 8,04\% por HF, 4,59\% peIa RIFI e 21,83\% pel o ELISA. O teste de ELISA foi o mais sensível para todos os grupos. Concl ui-se que a RIFI ainda não éferramenta útil para diagnóstico desta protozoose. O teste de ELISA, de fácil execução, foi fei to em $1 / 3$ do tempo usado para HF e RIFI, mel horando a qualidade do diagnósti co. Recomenda-se o ELISA como método de diagnósti co nos caso suspei tos de infecções com E. histolytica.

Palavras-chave Entamoeba histolytica; Amebíase; Diagnóstico; ELISA
\end{abstract}


Introdução

O diagnóstico laboratorial da amebíase intestinal é feito tradicionalmente por pesquisa do parasita nas fezes. Em geral, formas císticas são encontradas em fezes consistentes e trofozoíticas em material fecal diarréico ou pastoso. Contudo, a inexperiência técnica, a eliminação intermitente do cisto de Entamoeba histolytica/ Entamoeba dispar (Walsh, 1986) e a não diferenciação morfológica com outras amebas intestinais, leucócitos e artefatos podem promover erros no diagnóstico microscópico (Brucker, 1992). Além disso, os métodos coproscópicos não detectam parasitas rompidos (Healey, 1978) e não possibilitam a diferenciação entre a $E$. histolytica e E. dispar (Braga et al., 1996). Apesar dessas limitações e da baixa sensibilidade, tais métodos têm sido os de escol ha para o diagnóstico de amebíase intestinal (Ravidin, 1994).

No imunodiagnóstico, a reação de imunofluorescência indireta (RIFI) para pesquisa de anticorpos específicos contra o parasita no soro do paciente e o ensaio imunoenzimático (ELISA) para detecção de coproantígenos nas fezes têm sido empregados como alternativa diagnóstica. Ambas as técnicas podem ser utilizadas para o diagnóstico de casos isolados ou para estudos epidemiológicos (Feitosa, 1986; Jelinek et al., 1996; Haque et al., 1998), mostrando superior especificidade e sensibilidade no diagnóstico em relação à microscopia (KatzwinkelWladarsch et al., 1994).

A aplicação de novas metodologias para o diagnóstico específico da E. histolytica, facilitando principalmente a determinação da prevalência de portadores assintomáticos (Martínez-Palomo \& Espinosa-Cantellano, 1998), pode levar ao maior controle desta patologia. A situação da amebíase em Belém é pouco conhecida, razão pela qual requer dados que permitam traçar o perfil tanto da forma intestinal quanto da extra-intestinal, a última relatada como grave problema na cidade em foco (Salles et al., 1998). Este trabal ho tem por objetivo principal comparar métodos coproscópicos e imunológicos utilizados no diagnóstico de amebíase intestinal em uma amostra da população da área metropolitana de Belém.

\section{Material e métodos}

No período de outubro a novembro de 1998 foram analisadas 438 amostras fecais de pacientes (adultos e crianças) positivos para Entamoeba sp. pelo método direto, provenientes do Laboratório de Enteroparasitoses do Instituto
Evandro Chagas (Grupo I, n =46), amostras fecais e os respectivos soros de adultos atendidos no Hospital da Polícia Militar do Estado do Pará durante um mês (Grupo II, n =87) e amostras fecais diarréicas de crianças do Projeto Sentinela para gastroenterites do Serviço deVirologia do Instituto Evandro Chagas (Grupo III, $n=305)$. Os três grupos são homogêneos quanto à condição sócio-econômica e cultural, que é precária. Nos grupos I e III, para detecção de formas parasitárias (cisto e/ ou trofozoíto) foi utilizado o método direto com lugol (MD) e o método de flutuação de FAUST e colaboradores (MFF); para pesquisa do coproantígeno anti-GIAP (proteína de aderência inibidora da galactose) de E. histolytica foi empregado o teste de ELISA (Techlab, Blacksburg, Estados Unidos). No grupo II todas as amostras foram avaliadas simultaneamente pelo MD, hematoxilina férrica (HF), o MFF e, para detecção de coproantígenos, o teste de ELISA. Neste mesmo grupo foi usada a RIFI para a pesquisa de anticorpos IgG no soro, utilizando-se antígenos de culturas axênicas de E. histolytica e conjugado anti-IgG marcado com isotiocianato de fluoresceína (Salck, Brasil). Para determinar a significância estatística entre os grupos estudados recorreu-se ao teste do $\chi^{2}$ - através do programa estatístico EPIINFO versão 6.0 -, aplicandose o teste de McNemar para determinar a significância entre os testes utilizados.

\section{Resultados}

A positividade para E. histolytica na amostra estudada de acordo com os métodos empregados foi 10,50\% (46/438) para MD + MFF, 8,04\% (7/87) para HF, 4,59\% (4/87) para RIFI e 28,99\% (127/438) para o ELISA. Observou-se maior presença de E. histolytica nos pacientes de faixa etária superior a 14 anos (36,8\%, 46/125) (Tabela 1). O teste de pesquisa de coproantígenos mostrou-se mais eficiente para detecção da amebíase intestinal, demonstrando sensibilidade maior do que os métodos coproscópicos (McNemar, $\left.\chi^{2}-p<0,005\right)$.

No grupo II ( $\mathrm{n}=87$ ), em que as amostras foram estudadas pelos quatro métodos (coproscópicos e imunológicos), o teste coproscópico $(4,59 \%)$ e a RIFI (4,59\%) apresentaram resultados similares e inferiores aos observados pela HF (8,04\%). O teste de HF detectou um número de amostras positivas inferiores ao teste de ELISA (21,83\%). Aquela de detecção de coproantígenos evidenciou-se também significantemente mais eficiente para o diagnóstico de amebíase intestinal ( McNemar - p <0,005). 


\section{Discussão}

A prevalência de amebíase intestinal no Brasil deve ser reavaliada, por acreditar-se que há superestimativa desta protozoose em decorrência de os métodos classicamente empregados no diagnóstico não diferenciarem a forma patogênica da não-patogênica. A positividade presente no estudo por métodos coproscópicos e imunoenzimático confirma os dados da literatura. Entretanto, em estudos efetuados em populações indígenas da região norte, Miranda et al. (1998) e Martins \& Tavares (1999) - utilizando o método de Hoffman - detectaram alta prevalência de amebíase intestinal. A diferença marcante entre a positividade encontrada em nosso estudo e as observadas nos dois inquéritos citados pode ser atribuída ao fato de a comunidade indígena ser fechada, o que leva a maior circulação do parasita. Acrescente-se ainda o número de fal sos positivos que foram apontados pelo método de Hoffman nos referidos estudos, em que alguns artefatos podem ter confundido o(s) microscopista(s) com formas de protozoários, já que este método é mais indicado para a pesquisa de ovos pesados (helmintos).

A literatura mundial pertinente à prevalência de amebíase intestinal por faixa etária é controversa. Perez et al. (1997) e Braga et al. (1996), ao estudar indivíduos espanhóis e habitantes da região nordeste do Brasil, respectivamente, observaram maior prevalência desta protozoose na faixa etária entre 6 e 14 anos. Por sua vez, Kobayashi et al. (1995), ao analisarem amostra da população da cidade de Holambra, São Paulo, notaram maior positividade em pacientes maiores de 16 anos.

Os resultados da presente pesquisa mostram que a detecção de E. histolytica foi superior na faixa etária acima de 14 anos. Todavia, a diferença entre os dois grupos etários não foi estatisticamente significante, o que demonstra que o risco de transmissão independe da idade.

Como já verificado em estudos prévios, a HF evidenciou maior sensibilidade em relação
Tabela 1

Correlação de positividade entre os testes coproscópicos e detecção de coproantígenos por faixa etária.

\begin{tabular}{lrrrrr}
\hline & C+/E & C+/E- & C-/E & C-/E- & Total \\
\hline 0-14 Anos & 17 & 09 & 76 & 211 & 313 \\
Acima de 14 anos & $5,4 \%$ & $2,9 \%$ & $24,3 \%$ & $67,1 \%$ & \\
& 08 & 12 & 26 & 79 & 125 \\
Total & $6,4 \%$ & $9,6 \%$ & $20,8 \%$ & $63,2 \%$ & \\
& 25 & 21 & 102 & 290 & 438 \\
\hline
\end{tabular}

C = Coproscopia (MD e MFF); E = Teste ELISA para detecção de antígenos de E. histolytica.

ao MD e MFF; entretanto, este método depende de fatores de ordem técnica (preparação do esfregaço, coloração e da experiência do examinador), limitando seu uso corrente na pesquisa da amebíase intestinal. A baixa soropositividade encontrada pela RIFI pode ser decorrente do fato de o parasita permanecer no lúmen intestinal e, assim, não dá estímulo à resposta humoral. Além disso, a persistência de anticorpos pode depender não somente do tipo de imunoglobulina, mas também do número de infecções prévias (Stamm et al., 1976). Portanto, este método apresenta limitações expressivas no diagnóstico da amebíase intestinal.

O teste de ELISA, além de ser de fácil execução (Haque et al., 1994; Benzeguir \& Kettis, 1997), é realizado em $1 / 3$ do tempo da HF e da RIFI, revela mais E. histolytica do que a microscopia, além de sensibilidade de $86 \%$ e especificidade de $98 \%$ quando comparado com cultura (Martinez-Palomo \& Espinosa-Cantellano, 1998), o que contribui para a melhoria da qualidade do diagnóstico, detectando a forma patogênica. Recomendamos assim a sua inclusão como método de diagnóstico nos casos suspeitos de amebíase intestinal (Jelinek et al., 1996; Benzeguir \& Kettis, 1997; Haque et al., 1998), embora o seu custo ainda possa constituir fator limitante para o uso em larga escala.

\section{Agradecimentos}

Os autores agradecem a colaboração do Dr. Manoel Soares na revisão e sugestões a respeito do texto e do Prof. Ralph Lainson pela tradução do resumo. Este estudo recebeu apoio do Instituto Evandro Chagas/ Fundação Nacional de Saúde/ Ministério da Saúde e Programa Interinstitucional de Bolsa de Iniciação Científica/Conselho Nacional de Desenvolvimento Científico e Tecnológico/Instituto Evandro Chagas. 


\section{Referências}

BENZEGUIR, A. K. \& KETTIS, A. A., 1997. Evaluation of an Enzyme - Immunoassay test kit for diagnosis infections with Entamoeba histolytica. Archives of Medical Research, 28 (Sup.):276-278.

BRAGA, L. L.; LIMA, A. A.; SEARS, C. L.; NEWMAN, R. D.; WUHIB, T.; PAIVA, C. A.; GUERRANT, R. L. \& MANN, B. J., 1996. Soroepidemiology of Entamoeba histolytica in a slum in northeastern Brazil. American Journal of Tropical Medicine and Hygiene, 55:693-697.

BRUCKER, D. A., 1992. Amebiasis. Clinical Microbiology Review, 5:356-369.

FEITOSA, L. F. M., 1986. Aspectos da Amebíase Intestinal eHepática no Hospital Universitário Getúlio Vargas, Manaus - AM. Dissertação de Mestrado, Belo Horizonte: Faculdade de Medicina, Universidade Federal de Minas Gerais.

HAQUE, R.; ALI, I. K.; AKTHER, S. \& PETRI Jr., W. A. 1998. Comparison of PCR, isoenzyme analysis, and antigen detection for diagnosis of Entamoeba histolytica infection. Journal of Clinical Microbiology, 36:449-452.

HAQUE, R.; NEVILLE, L. M.; WOOD, S. \& PETRI J r., W. A., 1994. Short report detection of Entamoeba histolytica and Entamoeba dispar directly in stool. American Journal of Tropical Medicine and Hygiene, 50:595-596.

HEALEY, G. R., 1978. Parasitology. In: Proceedings of a Symposium on Waterbone Transmission of Giadiasis (W. Jakubowski \&J. C. Hoff, eds.), pp. 92-103, Washington, D.C.: Environment Protection Agency.

JELINEK, T.; PEYERL, G.; LOSHER, T. \& NOTHDURFT, H. D., 1996. Evaluation of an antigen - Capture enzyme immunoassay for detection of Entamoeba histolytica in stool sample. European Journal of Clinical Microbiology and Infectious Diseases, 15:752-755.
KATZWINKEL-WLADARSCH， S.; LOSCHER，T. \& RINDER, H., 1994. Direct amplification and differentiation of pathogenic and nonpathogenic Entamoeba histolytica DNA from specimens. American Journal of Tropical Medicine and Hygiene, 51:115-118.

KOBAYASHI, J.; HASEGAWA, H.; FORLI, A. A. NISHIMURA, N. F.; YAM ANAKA, A.; SHIMABUKURO, T. \& SATO, Y., 1995. Prevalence of intestinal parasitic infection in five farms in Holambra, São Paulo, Brazil. Revista do Instituto de Medicina Tropical deSão Paulo, 37:13-18.

MARTINEZ-PALOMO， A. \& ESPINOSA-CANTELLANO, M., 1998. Amoebiasis: New understanding and new goals. Parasitology Today, 14:1-3.

MARTINS, S. J. \& TAVARES, A. M., 1999. Parasitoses intestinais no município de Novo Airão - AM, Brasil, 1997-1998. Revista da Sociedade Brasileira de Medicina Tropical, 32 (Sup. 1):314.

MIRANDA, R. A.; XAVIER, F. B. \& MENEZES, R. C. 1998. Intestinal parasitism in indigenous community in southwestern Pará State, Brazil. Cadernos de Saúde Pública, 14:507-511.

PEREZ, A. C.; ARIZA, A. C.; UBEDA, O. J. M.; GUEVARA, B. D. C.; ROJAS, A. M. \& LOZANO, S. C., 1997. Epidemiology of children's intestinal parasitism in the Guadalquivir Valley, Spain. Revista Española de Salud Publica, 71:547-552.

RAVIDIN, J. I., 1994. Diagnosis of invasive amebiasis Time to end morphology era. Gut, 35:1018-1021.

SALLES, J. M.; SALLES, M.; SALLES, J. M.; BICHARA, C. N.: PÓVOA, M. M. \& MACHADO, R. L. D., 1998. Monografia de Amebíase(J. M. Salles, ed.), pp. 112, São Paulo: Rhodia.

STAM M, W. P.; ASHLEY, M. J. \& BELL, K., 1976. The value of amoebic serology in an area of low endemicity. Transactions of the Royal Society of Tropical Medicineand Hygiene, 70:49-53.

WALSH, J. A., 1986. Amebiasis in the world. Archivos deInvestigación Médica, 17 (Sup. 1):385-389. 